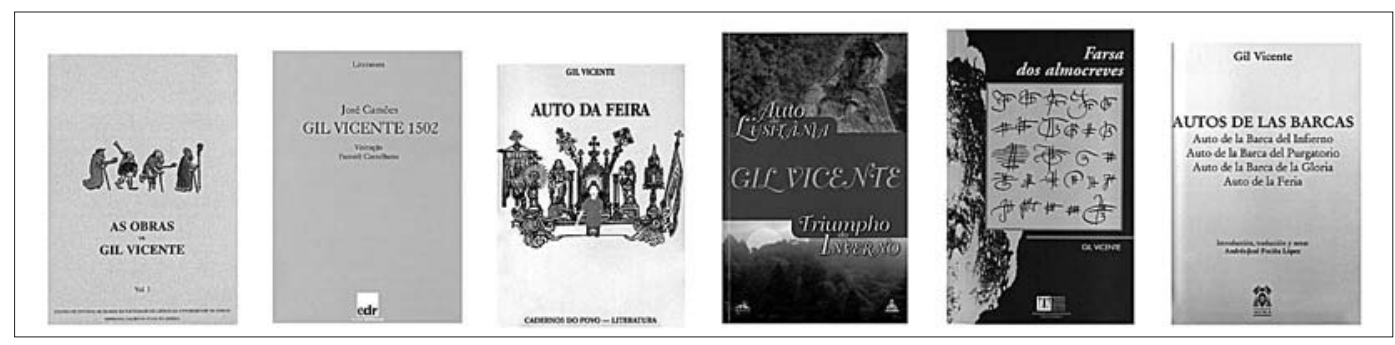

\title{
Celebrações vicentinas (2002-2003) Rol de livros - e não só - sem defeso
}

\author{
Isabel Pinto Carlos
}

As comemorações vicentinas por escrito: de 1502, representação de Visitação, ou rito de celebração do nascimento de D. João III, até 2002, exactamente cinco séculos passados. Como parte da memória, resta-nos celebrar; como teatro, é preciso dar a ver, procurando na letra a reconstituição do que terá sido a cena de outros tempos.

As iniciativas comemorativas conseguiram dar a efeméride por assinalada. E contribuiram para a divulgação da obra vicentina, sob a forma de conhecimento em construção.

Para a apresentação dos diferentes contributos escritos (tudo publicações de 2002 e 2003), que não pretende ser exaustiva, optámos pela sua distribuição por duas categorias, a saber: Catálogo e Crítica (subdividida em Publicações Colectivas e Individuais). Esta organização serve o propósito de tornar mais clara a exposição de um número ainda vasto de obras, assumindo a diversidade de desígnios (mais ou menos explícitos) e registos que as caracteriza.

\section{Catálogo}

As obras de Gil Vicente, direcção científica de José Camões, Lisboa, Centro de Estudos de Teatro da Faculdade de Letras da Universidade de Lisboa, Imprensa Nacional-Casa da Moeda, 2002, 5 vols. Edição da obra de Gil Vicente, em cinco volumes: vol. I (684 pp.) - apresentação das normas de transcrição; as "obras de devação", as "comédias" e parte das "tragicomédias" do livro terceiro da Compilação de 1562; vol. II (688 pp.) - as restantes "tragicomédias", as "farsas", as "cousas meúdas" do quinto livro e as obras fora da Compilação de 1562 (as "lições quinhentistas duplas" e Festa); vol. III (580 pp.) - fac-simile da Compilação de 1562; vol. IV (690pp.) - fac-símile da Compilação de 1586 e dos folhetos avulsos; vol. V (687 pp.) - o aparato crítico: Notas aos Textos, Textos Complementares às Notas, Índice de Figuras Históricas e Mitológicas, Índice de Personagens, Glossário e Bibliografia de Gil Vicente, que, além da divisão em catálogo (manuscritos e impressos) e crítica, inclui referência a bibliografias vicentinas anteriores, a obras atribuídas e a adaptações.
Destacam-se as normas de transcrição, pela clareza e economia de meios que as enformam e o aparato crítico, bastante completo, que ajuda efectivamente a ler, de muitas maneiras, os textos, deixando, no entanto, ao leitor a responsabilidade da interpretação.

No entanto, é bom ter à mão o CD-ROM (CNCDP, 2001), porque o manuseio de cinco pesados volumes, por vezes, pode parecer excessivo e limitativo. 0 saber vai adquirindo novos contornos e o que dantes era impensável como matéria de cogito, hoje revela-se-nos como ferramenta útil. Pesquisar é a palavra-chave que o CDROM nos permite actualizar. A título de exemplo: quantas vezes ocorrerá o vocábulo sebila no conjunto da obra vicentina? 0 livro dá-nos uma forma material de ler os textos, com mudança de página e cheiro, mas não nos dá o préstimo de um discreto motor de pesquisa.

José Camões (ed.), Gil Vicente 1502 (Visitação; Pastoril castelhano), Lisboa, Edições Duarte Reis, 2002, 117 pp. Edição crítica de Visitação e Pastoril castelhano, com primeiras representações em 1502. Contém uma Apresentação Crítica, na qual se reincide nos poucos dados biográficos conhecidos e se apresentam os autos editados; Nota de Edição, secção em que se dá conta de critérios gerais de transcrição e do restante conteúdo do livro, do qual se destaca: uma lista de Vocabulário e duas Bibliografias, subdivididas em catálogo e crítica. Como curiosidades: fac-símile da Visitação (Compilação de 1562) e duas traduções desse mesmo texto, uma da autoria de Afonso Lopes Vieira, outra de Paulo Quintela. Em suma, muita informação ao dispor do leitor que, mediante esta edição em formato de bolso, pode realmente ficar a conhecer os textos em causa, usufruindo, se assim o desejar, de linhas de leitura operativas na mediação entre a letra e a cena.

\section{Gil Vicente, Auto da feira, Cadernos do Povo -} Literatura, 2003, 96 pp.

Edição crítica de Auto da feira, acompanhada de notas explicativas do sentido do texto, sendo que algumas delas, a despeito da pertinência de outras, se imiscuem na leitura, condicionando o leitor para além do desejável. No Glossário é repetida alguma da informação dada em nota. 0 Posfácio, de Américo António Lindeza Diogo, analisa aspectos discursivos do texto editado, sublinhando o seu carácter alegórico. 


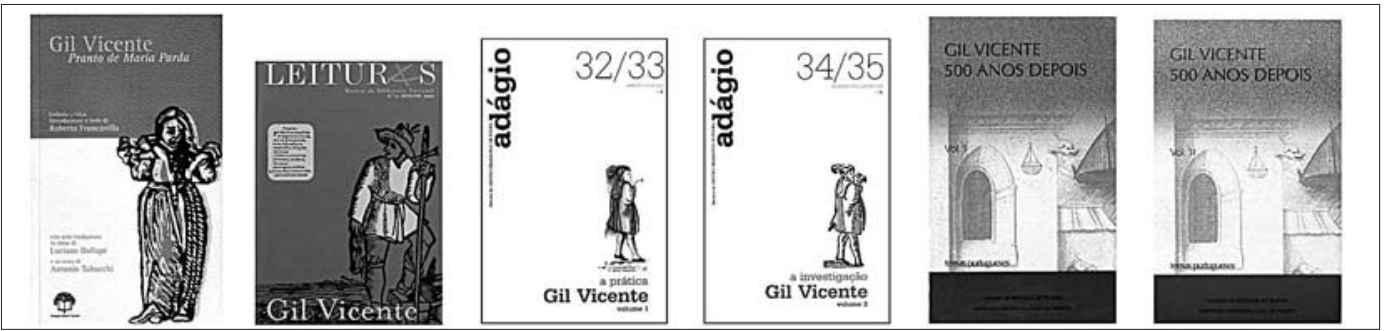

Gil Vicente, Auto da Lusitânia, seguido de Triumpho do Inverno, Lisboa, Hugin, 2003, 104 pp.

Assinalando a data de 7 de Junho de 1502 (representação de Visitação), o volume, iniciativa conjunta da Câmara Municipal de Sintra e da Hugin editores, contém a transcrição (mais ou menos) diplomática de Auto do Lusitânia e de Triunfo do Inverno. A escolha dos textos decorre do facto de, em ambos, Sintra ser evocada (através da sua serra). Face à ausência dos respectivos critérios e à omissão dos responsáveis pela fixação do texto, pouco mais se pode acrescentar.

Xoán Carlos Lagares (ed.), Farsa dos almocreves, A Coruña, Biblioteca-Arquivo Teatral "Francisco Pillado Mayor", 2003, 138 pp.

Edição crítica de Farsa dos Almocreves, composta pelos seguintes itens: Introdução, em que, partindo das incertezas biográficas relativas a Gil Vicente, se alude ao sentido da peça enquanto denúncia do conceito de "aderência"; Nota Lingüística, que, através da consideração de diferentes niveis de análise gramatical, procura, a um tempo, reconstituir, ainda que de forma parcelar, a língua de Quinhentos e atestar Critérios de Edição; Farsa dos almocreves, a edição propriamente dita, com notas que visam desde clarificar o sentido de palavras de uso menos frequente até cotejar diferenças para com edições anteriores; por último, Aparato de Variantes permite localizar cada uma das intervenções do editor sobre o original (Compilação de 1562), do qual se faz constar uma reprodução fac-similar.

Andrés-José Pociña López (trad.), Autos de las barcas Universidad de Alcalá, 2002, 147 pp.

Tradução de três autos de Gil Vicente para castelhano, em verso livre, a partir da edição da Lello \&t Irmão (Porto, 1965), a saber: as duas primeiras Barcas e o Auto da feira. A terceira Barca, a da Glória, encontra-se originalmente em castelhano (com excepção das rubricas), e em relação a esta adopta-se a edição de Thomas R. Hart em Obras Dramáticas Castellanas (Madrid, Espasa-Calpe, 1975). Neste conjunto, o Auto da feira parece surgir com função complementar. Um capitulo introdutório faz uma resenha do autor, da sua obra e do contexto histórico, a par com algumas consideracõos sobre os textos editados e respectivos critérios (gerais) de tradução.

Os quatro autos estão anotados, procurando determinar referentes da época, esclarecer termos mais obscuros e fornecer informações de carácter geral, eventualmente pouco acessiveis ao leitor médio espanhol.

Roberto Francavilla (trad.) et al., Pranto de Maria Parda, Protagon Editori Toscani, 2002, 127 pp.
Edição crítica e tradução para italiano de Pranto de Maria Parda, com uma Nota Previa, por Antonio Tabucchi, e com outra tradução, desta feita em rima, em apêndice, da autoria de Luciano Dallapé. Integrando observações genéricas sobre Gil Vicente e a sua obra (em Gil Vicente), e contextualizando não só o texto em causa bem como, em particular, a personagem Maria Parda (em II Pranto de Maria Parda), a edição adopta a transcrição de Paul Teyssier em La plainte de Maria la Noiraude (Paris, Chaindegne, 1995), estabelecida, à semelhança da tradução, a partir da Compilação de 1562. A par com a de elucidário, as notas detêm a função de confrontar o texto da Compilação com o da folha volante, supostamente anterior, incluida no catálogo Palha.

\section{Crítica}

\section{Publicações Colectivas}

Leituras: Revista da Biblioteca Nacional, n. ${ }^{\circ} 11,2002$, $223 \mathrm{pp}$.

Número totalmente dedicado a Gil Vicente, dividido em três partes: Editorial, com apresentação de Carlos Reis, e um texto introdutório de José Augusto Cardoso Bernardes, no qual se sublinha o "significado intrinsecamente artístico (literário e teatral)" da efeméride; Visitação de Gil Vicente, assim é denominada a parte que agrupa os ensaios e respectivas temáticas que perpassam na obra vicentina, e que vão desde o testemunho, registo pessoal do convivio com a obra do autor, passando por leituras actuais de determinados "aitos", que cruzam a letra com os propósitos da cena, até ao escrutinar de tradições em busca de novos sentidos textuais. Nesta secção, figuram ainda, a título póstumo, dois dossiês elaborados, no âmbito de um seminário, por Paul Teyssier, que fazem parte de uma iniciativa mais vasta de promoção dos dicionários antigos enquanto fonte privilegiada para a leitura de autores medievais e clássicos; Conhecer na BN: Gil Vicente, terceira e última parte da revista dedicada às compilações vicentinas disponiveis na Biblioteca Nacional.

Adágio: Revista do Centro Dramático de Évora, n. ${ }^{\circ} \mathrm{s}$ 32 / 33 e 34 / 35, dir. José Carlos Faria, Setembro de 2002 - Julho de 2003, 142+142 pp.

Dois volumes dedicados a Gil Vicente: o 32/33 sob a égide da prática, o 34/35 votado à investigação. No primeiro destes, deparamos com a memória cronológica das criações do Cendrev a partir de peças vicentinas, cujo início remonta a 1978, com a encenação de 0 velho da horta, através da recuperação de fichas técnicas de espectáculos e de textos dos programas, com direito a críticas e a dados estatísticos. 

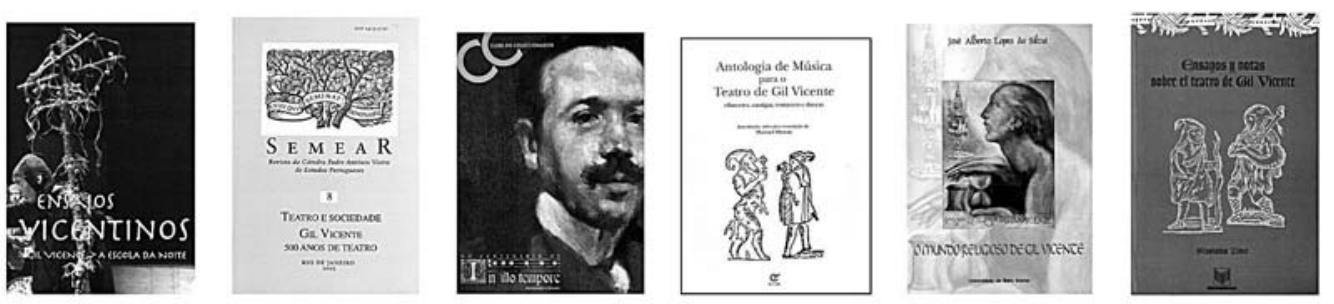

Quanto à investigação, a tábua de matérias compreende: Os Textos e os Géneros, secção que é consagrada a determinadas linhas de estudo, como a dos provérbios e a da categoria tempo, em confronto com os géneros possiveis; Os Intertextos e os Temas, conjunto de exercícios de intertextualidade, em paralelo com leituras simultaneamente temáticas e ideológicas; Os Palcos e a Escola, relato na primeira pessoa de um percurso dramatúrgico, em articulação com uma retrospectiva do lugar ocupado pelo texto vicentino nos programas escolares; 0 Teatro e a Música, tentativa de identificação de diferentes géneros musicais profanos na obra de Gil Vicente; Traduzir na Voz e na Letra, duas entrevistas: a Mário Barradas, por José Alberto Ferreira, e a Anne-Marie Quint, por Christine Zurbach.

Maria João Brilhante et al. (orgs.), Gil Vicente 500 anos depois: Actas do Congresso Internacional realizado pelo Centro de Estudos de Teatro da Faculdade de Letras da Universidade de Lisboa, Lisboa, Imprensa Nacional-Casa da Moeda, 2003, 2 vols., 520+454 pp. A circunstância de um congresso (Junho de 2002), à guisa de celebração, documentada em dois volumes de matérias suficientemente abrangentes para dar por homenageada a versatilidade do autor. Quer no âmbito das Conferências, quer no das Comunicações, diferentes aspectos dos estudos vicentinos são explorados, contribuindo tanto para a sua actualização como para a sua renovação; matérias de sempre, como as fontes, os géneros e o plurilinguismo, redefinidas por abordagens deste início de século; o desafio da leitura de uma letra que, a cada intervalo de tempo, se afasta de nós, leitores do séc. XXI, mas mantém a sua vitalidade, à luz da problemática da edição, com ou sem o préstimo das novas tecnologias. A este respeito, também a tradução se assume cada vez mais como compromisso para a divulgação de uma obra que se quer de todos. Linhas de leitura, em estreia ou apenas revisitadas, fazendo ou não uso da perspectiva comparatista, foram igualmente partilhadas, autorizando novas relações entre o texto e a cena. Ponto indispensável nesta ordem de trabalhos foi a análise desenvolvida em torno da presença de Gil Vicente no currículo escolar (entre 1888 e 1954). Para encerramento, a Mesa-Redonda, com a participação de encenadores, actores, críticos e estudiosos, súmula de memórias e perspectivas.

José Augusto Cardoso Bernardes (org.), Ensaios vicentinos, Coimbra, A Escola da Noite, 2003, 358 pp. Volume com função documental, que pretende juntar duas efemérides: os dez anos da companhia teatral A Escola da Noite e os quinhentos decorridos sobre a primeira representação do Auto da Visitação. Numa primeira parte, surgem os Ensaios Vicentinos, de diferentes autores, correspondendo cada um deles a um texto de Gil Vicente já trabalhado pela companhia. As abordagens propostas relevam para o conhecimento da obra vicentina, na medida em que convocam saberes que, mediante a descoberta de novos sentidos, conseguem desenvolver e aprofundar. Neste âmbito, a articulação entre a componente estético-literária e as circunstâncias histórico-sociais, a funcionalidade do discurso faceto e da prática teatral em si, a discussão dos géneros, a análise de personagens e a indexação das fontes são contributos a destacar.

Num segundo momento, Gil Vicente: Actos de memória e criação, é apresentado um conjunto de informações de vária ordem - reflexões artísticas ligadas à concepção dos espectáculos, número de sessões e espectadores, registos iconográficos relativos às produções, etc. - para o historial do métier da companhia.

Semear: Revista da Cátedra Padre António Vieira de Estudos Portugueses, n. ${ }^{\circ}$, Rio de Janeiro, 2003, $340 \mathrm{pp}$.

Volume que reúne as comunicações ao X Seminário Internacional da Cátedra Padre António Vieira de Estudos Portugueses (Outubro de 2002), durante o qual Gil Vicente foi figura central, em mais uma iniciativa do quinto centenário. Com honras de abertura, encontramos uma sistematização do tratamento cénico dado aos textos vicentinos entre 1998 e 2002 em Portugal. Em destaque, alguns aspectos particulares da obra vicentina, como as personagens, o imaginário (alegadamente insurrecto) e a perspectiva, a questionar, sobre a expansão e o império. As fontes da obra vicentina, bem como os géneros, são igualmente tema de análise. As incursões pelo teatro brasileiro contemporâneo "pontificam", enquanto os exercicios de indole comparatista se assumem como garante da vitalidade do diálogo entre autores. Por último, deparamos com o registo escrito da mesa-redonda com directores teatrais, realizada no âmbito do referido seminário.

\section{Publicações Individuais}

José Camões, "500 anos do Monólogo do vaqueiro, o nascimento do teatro ibérico", in Clube do Coleccionador, n. ${ }^{\circ}$ 2, CTT / Correios de Portugal, 2002, pp. 6-8.

Assinala-se, mais uma vez, a efeméride da representação de Monólogo do vaqueiro (ou Visitação), sintetizando os poucos dados biográficos conhecidos do autor e os 
principais géneros, respectivos propósitos e condicionantes. De Gil Vicente ainda se diz que "foi o último dos antigos e o primeiro dos modernos", na encruzilhada entre a Idade Média e o Renascimento.

Manuel Morais, Antologia de música para o teatro de Gil Vicente (vilancetes, cantigas, romances e danças), Lisboa, Estar-editora, 2002, 63 pp.

0 autor percorreu atentamente a obra de Gil Vicente em busca de todo e qualquer vestígio musical, resgatando incipits e versos de vilancetes, cantigas, romances, chançonetas e ensaladas, referências à música sacra, bem como nomes de alguns músicos seus contemporâneos, edificando o que o próprio designa "um corpus assaz significativo deste repertório". Em jeito de complemento, algumas questões residuais: Vicente acumularia os talentos de compositor e músico prático? A quem caberia a responsabilidade de cantar e tanger nos autos vicentinos?

José Alberto Lopes da Silva, 0 mundo religioso de Gil Vicente, Covilhã, Universidade da Beira Interior, 2002, $314 \mathrm{pp}$.

Numa primeira parte, é descrita a sociedade em que se inseria Gil Vicente, dando particular atenção à Igreja.

Num segundo momento, constituído, no essencial, por três capítulos, argumenta-se em diversos sentidos: o tema religioso, mais pretexto que pré-texto, chama a si três funções - divertimento, análise da realidade social e defesa da verdadeira religião; a crítica religiosa praticada remete não para um anticlericalismo, mas sim para o zelo de um cristão contra os maus-tratos dados à religião por certos membros da lgreja, etc.

A sua leitura contribui para um entendimento mais completo e fundamentado desta temática, ajudando ainda a reformular alguns aspectos à luz da premissa aqui introduzida: "É a sociedade, mais que a religião, o tema fundamental da sua obra".

Eneida Bomfim, $O$ traje e a aparência nos Autos de Gil Vicente, Rio de Janeiro e São Paulo, Editora PUCRio e Edições Loyola, 2002, 229 pp.

Estudo que tem como objecto especifico as referências ao vestuário nos autos vicentinos. A análise incide sobre: os nomes das vestes, tomadas no todo ou em parte; tecidos e materiais de confecção; adornos; profissionais e oficios; verbos associados às fases e modalidades de execução de materiais ou roupas; e ainda termos relacionados com a aparência. Numa primeira parte, a autora faz inferências gerais a partir do seu corpus, com o intuito de caracterizar o modo de vestir quinhentista, precisando correspondências entre indumentárias e grupos sociais. Num segundo momento, detém-se em

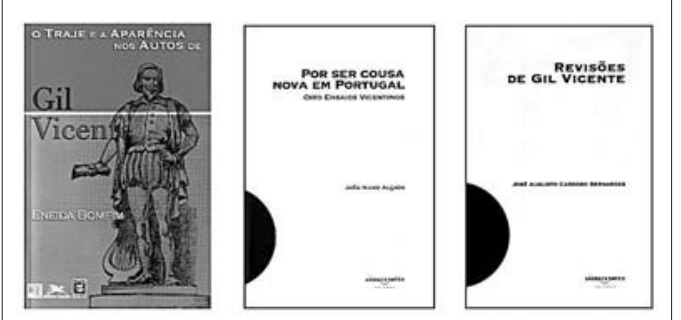

cada um dos elementos do corpus, cerca de cento e oitenta no total, especificando sentidos e pormenorizando matizes semânticas.

João Nuno Alçada, Por ser cousa nova em Portugal: Oito ensaios vicentinos, Coimbra, Angelus Novus, 2003, 569 pp.

Como o título indica, recolha de oito ensaios, nos quais se explicita o papel da cultura popular no teatro de Gi Vicente, aludindo a uma realidade histórica, na qual o poder e a misoginia marcam presença. Acresce dizer que a documentação iconográfica apresentada disponibiliza informação de outra ordem, à luz da qual se intentam rever leituras e significados, nomeadamente em relação a Auto da Lusitânia e a Templo d'Apolo.

José Augusto Cardoso Bernardes, Revisões de Gil Vicente, Coimbra, Angelus Novus, 2003, 208 pp. Conjunto de ensaios, dispersos por diferentes publicações e aqui reunidos num único volume. Estes textos compreendem desde temas transversais a todo o teatro vicentino, como é o caso da dialéctica entre Arte e História, até abordagens centradas em certas personagens (almocreves e ratinhos), e estudos de determinados autos (Juiz da Beira; Barcas). Os dois últimos ensaios, olhares sobre o todo da obra vicentina, correspondem a um ponto da situação relativamente à investigação em geral e às práticas da leitura e do ensino a ela associadas.

\section{Stanislav Zimic, Ensayos y notas sobre el teatro de} Gil Vicente, Madrid, Iberoamericana, 2003, 537 pp. Compilação de textos produzidos ao longo de mais de vinte anos de investigação, cujo objectivo é proporcionar, através de uma perspectiva global, a apreensão de múltiplas facetas da obra de Gil Vicente, clarificadas por reflexões de cariz fundamentalmente temático e estético. 0 critério para a ordem de apresentação dos ensaios, que abarcam toda a produção vicentina, é a data de representação, em alguns casos apenas conjectural, dos autos para que remetem. 